\title{
Short Term Outcome of Acute ST Elevation Myocardial Infarction in a Tertiary Care Cardiac Center
}

\author{
Hemant Shrestha, Ratna M Gajurel, Chandra M Poudel, Sanjeev Thapa, Arun Sayami \\ Department of Cardiology, Maharajgunj Medical Campus, Manmohan Cardiothoracic Vascular and Transplant \\ Center, Institute of Medicine, Kathmandu, Nepal
}

\section{Corresponding author:}

Hemant Shrestha, MD, DM

Department of Cardiology, Maharajgunj Medical Campus, Manmohan Cardiothoracic Vascular and Transplant Center, Institute of Medicine, Kathmandu, Nepal

Email: drhemantshrestha@gmail.com

Submitted : Jul 14, 2020

Accepted : Oct 3, 2020

\begin{abstract}
Introduction

Acute ST Elevation Myocardial infarction (STEMI) is a cardiovascular emergency and is associated with significant adverse short and long-term outcome. The objective of this study was to determine the shortterm outcome in terms of heart failure, myocardial reinfarction, stroke, hospital readmission and mortality in patients admitted with STEMI

\section{Methods}

It was a prospective observational study conducted at Manmohan Cardiothoracic Vascular and Transplant Center, Kathmandu from May 2014 to April 2015. All patients admitted with diagnosis of STEMI during study period were enrolled. Patients were treated on the basis of existing guidelines. Mode of management, adverse outcomes and mortality of patients during the study period were evaluated. The discharged patients were followed up for 30 days. Statistical analysis was performed with SPSS version 20. Ethical approval was taken from the Institutional Review Committee of Institute of Medicine.

\section{Results}

The median duration of presentation was 20 hours, and only $40 \%$ of the patients presented within 12 hours of symptom onset. Primary PCI was performed in 50 (33\%), thrombolysis was performed in 29(19\%) and conservative medical management was done in 72 (48\%) patients. Overall outcome occurred in 52 (37.7\%) patients. In hospital and 30 day mortality was 14 (9.2\%) and 17 (11\%) respectively. Heart failure was present in 28(18.5\%), myocardial reinfarction 8 (5\%), stroke 4 (2.6\%), and hospital readmission was 18 (12\%). Conservatively treated patients had significantly more adverse outcomes $(p=0.02)$. More patients in conservatively managed group had hospital readmission. $(p=0.04)$
\end{abstract}

\section{Conclusion}

There were more overall adverse outcomes in conservatitley managed group which is mainly due to more hospital readmission.

Keywords: Primary PCI, short term outcome, STEMI, thrombolysis 


\section{INTRODUCTION}

S elevation myocardial infarction (STEMI) is a clinical syndrome defined by characteristic symptoms of myocardial ischemia accompanied by persistent elevation the ST segment on electrocardiograph (ECG) and subsequent release of biomarkers of myocardial necrosis. ${ }^{1}$ Acute $\mathrm{Ml}$ occurs when intra arterial thrombus propagates and completely occlude blood flow within the artery, resulting in ischemia and necrosis of cardiomyocytes distal to the obstruction. ${ }^{2}$ Acute $\mathrm{Ml}$ causes substantial morbidity and mortality worldwide. ${ }^{3}$

Management of STEMI is directed towards reperfusion therapy, either by thrombolysis or primary percutaneous coronary artery intervention (PPCl). PPCl is the best available option and various studies have shown that $\mathrm{PPCl}$ is better than thrombolysis in reducing cardiovascular mortality and morbidity. ${ }^{4,5}$ If the patient presents after 12-24 hours of symptoms onset without ongoing pain or complications, they are usually kept in conservative medical management and percutaneous coronary intervention (PCl) can be planned later. Adverse outcomes are usually based on the mortality, myocardial reinfarction, heart failure, stroke and recurrent hospital admission. Among patients with STEMI enrolled in trials, approximate 30day mortality rates were 13 percent with medical therapy alone, 6 to 7 percent with optimal fibrinolytic therapy, ${ }^{6}$ and as low as 3 to 5 percent with primary percutaneous coronary intervention (PCl) when timely performed.

In our country, there is limited data regarding the outcomes of acute STEMI. Few studies have been published which compare the early outcome of PPCI in acute STEMI. ${ }^{8}$ Outcomes related to thrombolysis and conservative treatment is not well studied. So, the general objective of the study was to know the short-term adverse outcome in hospital and after hospital discharge up to 30 days in acute STEMI in all three $\mathrm{PPCl}$, thrombolysis and conservatively managed groups. The specific objective was to determine the heart failure, myocardial reinfarction, stroke, recurrent hospital admission and mortality in these different groups.

\section{METHODS}

It was a prospective observational study conducted in Department of Cardiology, Manmohan Cardiothoracic Vascular and Transplant Centre (MCVTC), Maharajgunj, Kathmandu. Acute STEMI was diagnosed on the basis of third universal definition of myocardial infarction. ${ }^{9}$ Study period was one year from May 2014 to April 2015. Adult patients above 18 years, both male and female, diagnosed and admitted as acute STEMI were enrolled in the study. Excluded patients were those who died in ER before initiation of proper treatment, and those with medical surgical illness that precluded treatment (acute CVA, severe sepsis, ongoing UGI bleed).

Informed consent was taken from all patients. The Institutional Ethical Review Committee of Institute of Medicine approved the study.

All eligible acute STEMI patients were enrolled in the study. Presenting symptoms, general physical examination, and baseline investigations along with cardiac enzymes, ECG and echocardiography was performed at admission. Risk factors were determined on the basis of history and investigations.

Acute STEMI

$(n=166$, excluded $=15)$

Final number $=151$

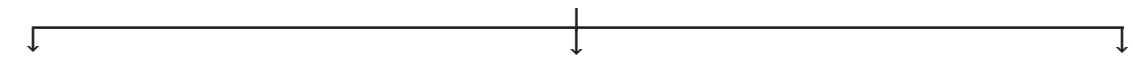

$\mathrm{PPCl}$
$\mathrm{n}=50(33 \%)$

- All patients presenting within 12 hours

- Patients presenting within 12-24 hours

and having ongoing chest pain

- Cardiogenic shock, Acute heart failure

irrespective of duration of symptoms

Excluded:

- Patients presenting after 24 hours

- Not giving consent

- Delay for PPCl

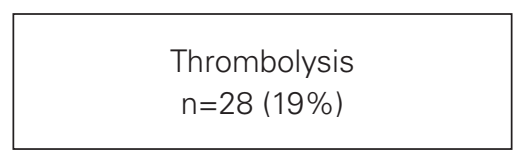

- Patients presenting within 12- 24 hours and not giving consent to PPCl

- Delay for PPCI

- No contraindications for thrombolysis

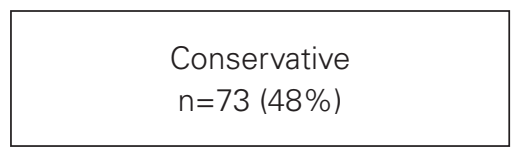

- Patients presenting after 24 hours - Patients presenting within 24 hours but not giving consent $\mathrm{PPCl}$ and

- Having contraindications for thrombolysis

Fig 1. Plan of management of STEMI patients 
Address of the patient was subdivided into those inside or outside Kathmandu valley.

Patients were managed according to the guidelines given by ACC/AHA in 2013. ${ }^{10}$ Depending upon the time duration at which patients presented, there were three groups of patients- Primary $\mathrm{PCl}$, Thrombolysis and Conservatively managed group. (Fig 1)

Non fatal outcome included heart failure, stroke, myocardial reinfarction and hospital readmission. Myocardial reinfarction was considered when ST elevation $\geq 0.1 \mathrm{mV}$ recurs, or new pathognomonic Q waves appear, in at least two contiguous leads, when associated with ischemic symptoms for 20 min or longer. ${ }^{9}$ Heart failure was defined as from crepts in chest, with S3 and raised JVP, to frank pulmonary edema. ${ }^{11}$ Stroke was defined as a clinical syndrome consisting of rapidly developing clinical signs of focal (or global in case of coma) disturbance of cerebral function lasting more than 24 hours or leading to death with no apparent cause other than vascular origin. ${ }^{12}$ Fatal outcome included in hospital and 30 day mortality. Overall adverse outcome was said to be present, if anyone of the fatal or nonfatal outcome occurred.

Depending upon the clinical status and requirement, some patients were followed up after 1-2 weeks, and all patients were called upon at 30 days after discharge. Those patients who didn't come for follow up, telephone call was made to know regarding their status. If mortality had occurred, it was noted with likely cause of death.

Statistical analysis was performed with SPSS version 20. For demographic profile, frequency and percentage distribution were obtained for each variable. Data were expressed as mean+ SD for continuous variables and as percentage for categorical variables. For continuous variables, differences between groups were compared with independent t-test. Chi-square test was used to detect linear association between type of treatment and adverse outcome. A two sided $p$ value of $<0.05$ was considered statistically significant.

\section{RESULTS}

There were total of 166 patients presented to MCVTC Emergency room (ER) with diagnosis of acute STEMI, and 151 patients were included in the study who fit in inclusion criteria.(Fig 1) The mean age was $59.0 \pm 13$ years. (Table 1) The mean age for male was $58.35 \pm 13$ years and female was $60.42 \pm 12$ years. The minimum age of presentation was 29 years and maximum age was 84 years. There were $103(68 \%)$ male and $48(32 \%)$ female. Majority of the patients $88(58 \%)$ were from inside Kathmandu valley, and 63(42\%) patients were from outside Kathmandu valley.
Table 1. Baseline characteristics of patients: demographics, risk factors, complications and management

\begin{tabular}{|c|c|}
\hline Variables & $\begin{array}{c}\text { Mean/ } \\
\text { Frequency }\end{array}$ \\
\hline $\begin{array}{l}\text { Age } \\
\text { Male } \\
\text { Female }\end{array}$ & $\begin{array}{l}59.0 \pm 13 \\
58.35 \pm 14 \\
60.42 \pm 12\end{array}$ \\
\hline Age $\geq 65$ years & $44(29 \%)$ \\
\hline $\begin{array}{l}\text { Sex } \\
\text { Male } \\
\text { Female }\end{array}$ & $\begin{array}{c}103(68 \%) \\
48(32 \%)\end{array}$ \\
\hline From outside Kathmandu valley & $63(42 \%)$ \\
\hline Referred from other center & $106(70 \%)$ \\
\hline $\begin{array}{l}\text { Median duration of presentation } \\
\text { Inside Kathmandu valley } \\
\text { Outside Kathmandu valley }\end{array}$ & $\begin{array}{l}20 \text { hours } \\
12 \text { hours } \\
28 \text { hours }\end{array}$ \\
\hline $\begin{array}{l}\text { Presentation } \\
\text { Within } 12 \text { hours } \\
\text { Within } 24 \text { hours }\end{array}$ & $\begin{array}{l}60(40 \%) \\
87(58 \%)\end{array}$ \\
\hline Hypertension & $105(70 \%)$ \\
\hline Diabetes mellitus & $43(28 \%)$ \\
\hline Dyslipidemia & $9(45.7 \%)$ \\
\hline Prior CVA & $6(4 \%)$ \\
\hline Renal Dysfunction & $11(7.3 \%)$ \\
\hline Prior CAD & $4(2.6 \%)$ \\
\hline Alcohol & $34(22.5 \%)$ \\
\hline Smoking & $82(54.3 \%)$ \\
\hline LV ejection fraction $\leq 40 \%$ ) & $72(48 \%)$ \\
\hline $\begin{array}{l}\text { Wall involvement } \\
\text { Anterior wall } \\
\text { Inferior wall }\end{array}$ & $\begin{array}{l}84(56 \%) \\
67(44 \%)\end{array}$ \\
\hline $\begin{array}{l}\text { Killip Class } \\
\text { I } \\
\text { II } \\
\text { III } \\
\text { IV }\end{array}$ & $\begin{array}{c}98(65 \%) \\
29(19 \%) \\
9(6 \%) \\
15(10 \%)\end{array}$ \\
\hline $\begin{array}{l}\text { Treatment received } \\
\text { Primary PCl } \\
\text { Thrombolysis } \\
\text { Conservative management }\end{array}$ & $\begin{array}{l}50(33 \%) \\
28(19 \%) \\
72(48 \%)\end{array}$ \\
\hline
\end{tabular}

The most common risk factors were hypertension (70\%), Smoking (54\%) and dyslipidemia (45.7\%). The overall median duration of presentation was 20 hours. For inside Kathmandu valley, median duration of presentation was 12 hours, while that for outside Kathmandu valley was 28 hours. Among 151 patients, $61(40 \%)$ patients presented within 12 hours, and $87(58 \%)$ patients presented within 24 hours. 
Table 2: Non fatal and fatal outcomes in each of the management group

\begin{tabular}{lccccc}
\hline \multirow{2}{*}{ Outcome } & \multicolumn{2}{c}{ Reperfusion } & Conservative & Total & p-value \\
\cline { 2 - 4 } & $\mathrm{PPCl}$ & Thrombolysis & management & & \\
\hline Heart Failure & $7(14 \%)$ & $5(18 \%)$ & $16(22 \%)$ & $28(18.5 \%)$ & 0.40 \\
Reinfarction & $1(2 \%)$ & $1(3.5 \%)$ & $6(8.2 \%)$ & $8(5 \%)$ & 0.15 \\
Stroke & $0(0 \%)$ & $1(3.6 \%)$ & $3(4.1 \%)$ & $4(2.6 \%)$ & 0.40 \\
Hospital readmission & $2(4 \%)$ & $3(11 \%)$ & $13(18 \%)$ & $18(12 \%)$ & 0.04 \\
Death & $7(14 \%)$ & $1(3.5 \%)$ & $9(12 \%)$ & $17(11 \%)$ & 0.30 \\
Overall outcomes & $11(22 \%)$ & $8(28.5 \%)$ & $33(45 \%)$ & $52(34.4 \%)$ & 0.02 \\
\hline
\end{tabular}

Anterior wall involvement $84(56 \%)$ was more as compared to Inferior wall 67(44\%). Majority of the patients presented in Killip Class I (65\%), followed by Killip Class II(19\%), Killip Class IV (10\%) and Killip Class III (6\%).

Total of 50(33\%) patients received Primary $\mathrm{PCl}$, 29(19\%) patients received Thrombolysis, and 72 (48\%) patients received conservative management. (Fig 2) Among 61 patients who presented within 12 hours, $37(60 \%)$ patients underwent primary $\mathrm{PCl}$, $23(38 \%)$ patients underwent thrombolysis and 1 patient was kept under conservative management. Among 87 patients who presented within 24 hours, $47(54 \%)$ patients underwent primary $\mathrm{PCl}$, $28(32 \%)$ patients underwent thrombolysis and $12(14 \%)$ patients were kept under conservative management. Drug eluting stents (DES) was kept in $39(78 \%)$ patients, bare metal stents (BMS) was kept in $7(14 \%)$ patients and simply balloon angioplasty was done in $4(8 \%)$ patients. Streptokinase was given as thrombolytic agent in 16 (57\%)patients, while tenecteplase was given in 12 (43\%) patients.

Heart failure was present in $28(18.5 \%)$ patients, myocardial reinfarction in $8(5 \%)$ patients, stroke in $4(2.6 \%)$ patients, hospital readmission in $18(12 \%)$ patients and death in $17(11 \%)$ patients. (Table 2)

There were $7(14 \%)$ patients in primary $\mathrm{PCl}$ group, $5(18 \%)$ in thrombolysis group and $16(22 \%)$ in conservatively managed group that had heart failure.

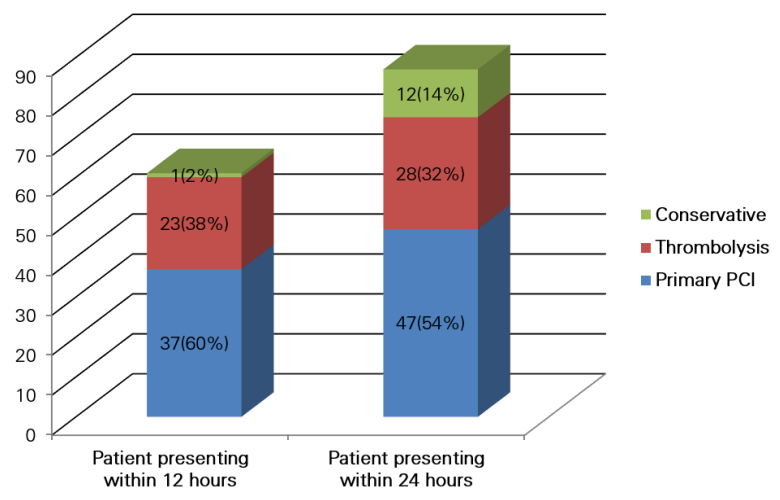

Fig 2. Management of patients presenting within window period
One $(2 \%)$ patient in primary $\mathrm{PCl}$ group, $1(3.5 \%)$ in thrombolysis group and $6(8.2 \%)$ in conservatively managed group had myocardial reinfarction. No stroke occurred in primary $\mathrm{PCl}$ group. One (3.6\%) in thrombolysis group and $3(4.1 \%)$ in conservatively managed group had stroke. Two (4\%) patients in primary $\mathrm{PCl}$ group, $3(11 \%)$ in thrombolysis group and $13(18 \%)$ in conservatively managed group had hospital readmission for various causes during 30 days of $\mathrm{Ml}$. Overall adverse outcome occurred in $52(34.4 \%)$ patients. Eleven $(22 \%)$ patients in primary $\mathrm{PCl}$ group, $8(28.5 \%)$ in thrombolysis group and $33(45 \%)$ in conservative management group had major adverse outcome. As compared to reperfusion therapy, there were significantly more overall adverse outcome in conservatively managed group $(p=0.02)$. This was largely driven by increased hospital readmission in conservatively managed group, whereas there was no significant difference of other outcomes in both reperfused and conservatively managed group.

There were total of $17(11 \%)$ thirty-day deaths. Seven $(14 \%)$ in primary $\mathrm{PCl}$ group, 1(3.5\%) in thrombolysis group and $9(12 \%)$ in conservatively managed groups had death. Three patients expired after hospital discharge, while in hospital mortality was $14(9.2 \%)$. There were more deaths in woman $10(20.8 \%)$ as compared to man $7(6.8 \%)$. About $53 \%$ of patients who presented in shock expired,

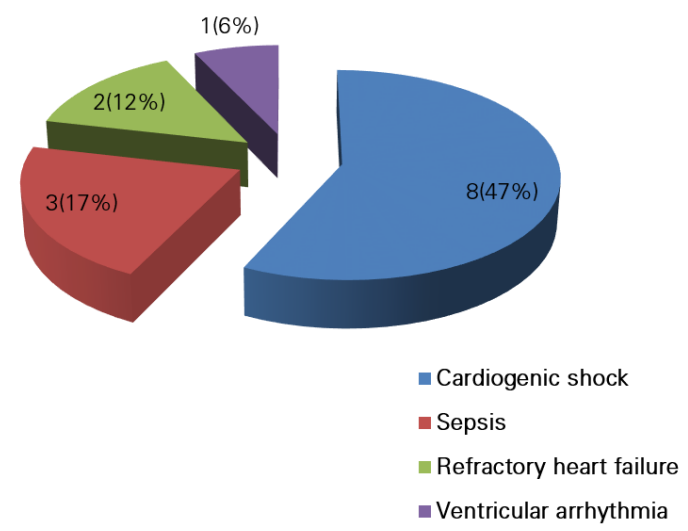

Fig 3. Causes of in-hospital death 
which was the most common cause of death (Figure 3). While excluding patients in shock, the mortality was $6.6 \%$.

\section{DISCUSSION}

The mean age of the patients was similar to other international studies. ${ }^{13-15}$ The gender difference of more male patients is seen not only in Nepal, but internationally. ${ }^{713,14}$ The incidence of CAD in female is less than male probably due to the protective role of estrogen in premenopausal woman, but its incidence increases as the age progresses and it is the leading cause of death in women. ${ }^{16}$

One of the striking features about risk factors was high prevalence of smoking. About 54.3\% of patients were current smoker. High prevalence of smoking was present in other studies in Nepal also. In western Nepal, it was about $80 \%{ }^{15}$ while in Kathmandu it was about $60 \% .{ }^{8}$ In NCDR registry in the USA, smoking was present in $31 \% .^{7}$ As smoking is the major risk factor for CAD, and its high prevalence in our country, every effort should be done to help people quit smoking not only to reduce the risk of CAD but also to reduce the risk of pulmonary diseases and malignancy.

The overall median duration of presentation or prehospital time (PHT) delay in this study was 20(1 to 120) hours which is high. The percentage of patients presenting within 12 hours of symptoms onset is $40 \%$ and those presenting within 24 hours is $58 \%$. The median PHT is 3.5 hours (1.2 to 15.2 hours) in the USA and 2.5 hours (1.5 to 8.7 hours) in the United Kingdom, 4.4 hours (1.8 to 13.3 hours) in South Korea and 4.5 hours (2.0 to 16.3 hours) in Japan. ${ }^{17}$ As earlier the reperfusion is performed better is the short and long term result, 4 effort should be directed to decrease the prehospital delay, which is markedly longer as compared to other countries. Studies have shown that patient may not perceive the acute symptoms, may not recognize the severity and importance of symptom, and there might be delay for call for help; so health care providers and policymakers should address in these areas to decrease the prehospital delay. ${ }^{18}$

Sixty percent of patients received $\mathrm{PPCl}$ and $38 \%$ of the patients received thrombolysis who presented within 12 hours of symptoms onset. Fifty four percent of patients received $\mathrm{PPCl}$ and $32 \%$ patients received thrombolysis who presented within 24 hours. This is similar to that of other countries. In National Cardiovascular Data Registry (NCDR) of the USA, primary $\mathrm{PCl}$ was performed in $83 \%$ and thrombolysis was performed in $12 \%$ and overall reperfusion therapy was performed in $93 \%$ of STEMI patients. ${ }^{7}$ Similarly, in European registry, $\mathrm{PCl}$ was performed in $61 \%$ and thrombolysis was performed in $33 \%$, and overall reperfusion therapy was performed in $94 \%$ of patients. ${ }^{19}$ This shows we are providing reperfusion therapy to those who presented within window period similar to that of western world. The median door to balloon time (DBT) was 100 (40 to 180) minutes, and the mean DBT was $97.6( \pm 32)$ minutes, which is comparable to that of other studies. ${ }^{7}$

Overall heart failure was present in 28(18.5\%) patients. Occurrence of heart failure varies across the world. In Kerala registry in India, heart failure was present in $2.7 \%,{ }^{14}$ in GRACE study $18 \%,{ }^{20}$ and in European registry $16.8 \% .{ }^{19}$ Slight increase in heart failure might be due inclusion of patients who were managed conservatively. Myocardial reinfarction occurred in $8(5 \%)$ patients. One $(2 \%)$ patient in primary $\mathrm{PCl}$ group, $1(3.5 \%)$ in thrombolysis group and $6(8.2 \%)$ in conservatively managed group had myocardial reinfarction. In the RIKS-HIA study done in Swedish population, reinfarction occurred in 2\% in $\mathrm{PCl}$ group and $3.4 \%$ in thrombolysis group. ${ }^{21}$ So the occurrence of reinfarction is slightly high when all groups are taken together but is similar to western world when taken separately for $\mathrm{PCl}$ and thrombolysis. Stroke occurred in $4(2.6 \%)$ overall patients but no stroke occurred in primary $\mathrm{PCl}$ group similar to other studies. ${ }^{14,19}$

Hospital readmissions are a quality of care indicator. After hospital discharge, hospital readmission is one of the factor leading to increased morbidity and mortality. There was rehospitalization in $18(12 \%)$ patients but only two $(4 \%)$ patients in primary $\mathrm{PCl}$ group, which is similar to that of other studies. ${ }^{22}$

Out of 17 deaths in the study period, $14(9.2 \%)$ were inhospital deaths and 3 were on follow up. Out of 15 patients who have presented in Killip Class IV, $8(53 \%)$ patients expired. Similar high mortality was seen in patients with STEMI presenting in cardiogenic shock. ${ }^{23,24}$ While excluding patients in shock, the mortality was $6.6 \%$. In Indian CREATE study, 30 day mortality was $9 \%,{ }^{13}$ and in GRACE study $8 \%{ }^{25}$ and in Hospital in Kerala study $8.2 \%{ }^{14}$ This shows that overall mortality is slightly higher than other studies. The reason behind this may be due to the fact that many patients in our study were kept in conservative management while majority of the patients in other studies underwent reperfusion therapy. Patient presentation was also quite late, and studies have shown that earlier the perfusion, better is the outcome. ${ }^{26,27}$ The high mortality in $\mathrm{PCl}$ group can be explained by studies showing high mortality in patients presenting in cardiogenic shock. ${ }^{28}$ There was more mortality in female. Several other studies have also shown female sex as a predictor of adverse cardiovascular outcome. ${ }^{29}$ More adverse outcome and mortality in female is found to be later age of presentation than men, lesser use of primary $\mathrm{PCl}$ and presence of more comorbid conditions. ${ }^{30}$ 
Overall adverse outcomes were significantly more in conservatively managed group $(p=0.02)$, which was mainly because of significant more hospital readmissions in conservatively managed group ( $p=0.04)$. Whereas, there was no significant difference of outcomes in other variables between two groups. This can be explained by small sample size, low number of event rates as well as short duration of study period.

The study was limited to one center. Sample size was small. The individual event rates were also less because of small sample size. The patients who expired at ER and who refused admissions were not included in the study.

\section{CONCLUSION}

Overall adverse cardiovascular outcome as well as recurrent hospital admission is higher in conservatively managed group.

\section{CONFLICT OF INTEREST}

None declared.

\section{REFERENCES}

1. Thygsen $K$, Alpert JS, Jaffe AS et al. Fourth Universal Definition of Myocardial Infarction (2018). J Am Coll Cardiol. 2018 Oct 30; 72(18): 2231-2264.

2. Libby P, Ridker PM, Maseri A et al. Inflammation and Atherosclerosis. Circulation. 2002 Mar; 105(9): 1135-43.

3. Marceau A, Samson JM, Laflamme N et al. Short and long term mortality after STEMI versus NSTEMI: A systematic review and meta analysis. J Am Coll Cardiol. 2013 March;Volume 61, Issue 10.

4. McManus DD, Gore J, Yarzebski J et al. Recent trends in the incidence, treatment, and outcomes of patients with STEMI and NSTEMI. Am J Med. 2011; 124:40-7.

5. Boersma E. Does time matter? A pooled analysis of randomized clinical trials comparing primary percutaneous coronary intervention and in-hospital fi brinolysis in acute myocardial infarction patients. Eur Heart J 2006; 27: 779-88.

6. An international randomized trial comparing four thrombolytic strategies for acute myocardial infarction. The GUSTO investigators. N Engl J Med 1993; 329:673.

7. Roe MT, Messenger JC, Weintraub WS et al. Treatments, Trends, and Outcomes of Acute Myocardial Infarction and Percutaneous Coronary Intervention. J Am Coll Cardio.2010; 56(4): 254-63.

8. Adhikari $C M$, Bhatta $Y D$, Malla $R$ et al. Outcomes of Primary Percutaneous Intervention at Sahid Gangalal National Heart Centre, Kathmandu, Nepal. Journal of Advances of Internal Medicine. 2013;02(01): 6-9.

9. Thygesen $K$, Alpert JS, Jaffe AS et al. Third universal definition of myocardial infarction. Circulation. 2012; 126:2020-35.

10. O'Gara PT, Kushner FG, Deborah D et al. 2013 ACCF/AHA Guideline for the Management of ST-Elevation Myocardial Infarction: A Report of the American College of Cardiology Foundation/American Heart Association Task Force on Practice Guidelines. Circulation. 2013; 127:e362-e425.

11. De Luca G, Amoud WJ, de Boer MJ et al. Impaired myocardial perfusion is a major explanation of the poor outcome observed in patients undergoing primary angioplasty for ST Elevation myocardial infarction and signs of heart failure. Circulation. 2004;109:958-961.

12. Hatano $S$. Experience from a multicenter stroke register: a preliminary report. Bulletin of the World Health Organization. 1976;54(5):541553.

13. Xavier D, Pais P, Devereaux PJ et al. Treatment and outcomes of acute coronary syndromes in India (CREATE): a prospective analysis of registry data. Lancet 2008; 371: 1435-42.

14. Mohanan PP, Mathew R, Harikrishnan $S$ et al. Presentation, management, and outcomes of 25748 acute coronary syndrome admissions in Kerala, India: results from the Kerala ACS Registry. European Heart Journal. 2013; 34: 121-129.

15. Paudel B, Paudel K. Western Nepal acute coronary syndrome (WestNPACS) registry: Characteristics, management and in- hospital outcome of patients admitted with acute coronary syndrome in western Nepal. Journal of GMC.2009;2(3):51-59.

16. Sharma K, Gulati M. Coronary Artery Disease in Women: A 2013 Update. Global Heart. 2013.

17. McKinley S, Dracup K, Moser DK, et al. International comparison of factors associated with delay in presentation for AMI treatment. Eur J Cardiovasc Nurs. 2004; 3:225-230.

18. Gartner C, Walz L, Bavernschmilt $E$ et al. The causes of delay in myocardial infarction. Dtsch Arztebl int. 2008;105(15):286-91.

19. Eurobservational Research programme Acute Coronary Syndrome Registry 2010. (Online) (Cited 2010 December 21). Available from UR: https://www.euroheartsurvey.org/.

20. Eagle KA, Goodman SG, Avezum A, et al. GRACE Investigators. Practice variation and missed opportunities for reperfusion in STsegment-elevation myocardial infarction: findings from the Global Registry of Acute Coronary Events (GRACE). Lancet 2002; 359: 373-7.

21. Stenestrand $U$, Lindbäck J, Wallentin $L$ et al. Long-term Outcome of Primary Percutaneous Coronary Intervention vs Prehospital and In-Hospital Thrombolysis for Patients With ST-Elevation Myocardial Infarction. JAMA. 2006;296(14):1749-1756.

22. Dunlay SM, Weston SA, Killian JM et al. Thirty Day Hospital Readmissions Following Acute Myocardial Infarction: A Community Study. Ann Intern Med. 2012 Jul 3; 157(1): 11-18.

23. Maskey A, Regmi SR, Dubey L et al. Primary Percutaneous Coronary Intervention (PPCI) in acute myocardial infarction complicated with cardiogenic shock in a newly emerging cardiac center in Nepal. J Res Med Sci. 2009 Mar-Apr; 14(2): 123-127.

24. Hochman JS, Sleeper LA, White HD et al. One year survival following early revascularizationfor cardiogenic shock. JAMA.2001; 285(2):190-2.

25. Fox KA, Goodman SG, Klein W, et al. Management of acute coronary syndromes. Variations in practice and outcome; findings from the Global Registry of Acute Coronary Events (GRACE). Eur Heart I 2002; 23: 1177-89

26. Boersma E, Mercado $N$, Poldermans $D$ et al. Acute myocardial infarction. Lancet. 2003; 361:847-858.

27. Bagai A, Dangas GD, Stone GW et al. Reperfusion strategies in Acute Coronary Syndromes. Circulation Research. 2014; 114:1918-1928.

28. Reynolds HR, Hochman JS. Cardiogenic Shock: current concepts and improving outcomes. Circulation. 2008; 117:686-697.

29. Radovanovic D, Erne $P$, Urban $P$ et al. Gender differences in management and outcomes in patients with acute coronary syndromes: results on 20,290 patients from the AMIS Plus Registry. Heart. 2007 Nov; 93(11): 1369-75.

30. Milcent C, Dormont B, Durand-Zaleski I et al. Gender Differences in Hospital Mortality and Use of Percutaneous Coronary Intervention in Acute Myocardial Infarction. Microsimulation Analysis of the 1999 Nationwide French Hospitals Database. Circulation. 2007; 115:833839 